\title{
The effect of acute swimming exercise on plasma melatonin levels in rats
}

\author{
Uzun $\mathrm{A}^{1}$, Baltaci AK ${ }^{2}$, Kilic $\mathrm{M}^{1}$, Mogulkoc $\mathrm{R}^{2}$ \\ School of Physical Education and Sports, Selçuk University, Konya - Turkey. baltaci61@yahoo.com
}

\begin{abstract}
Background: This study aims to determine the changes in plasma melatonin levels of rats performing acute swimming exercise, immediately following the exercise and after 24 and 48 hours.

Methods: The study included 40 Spraque Dawley species adult male rats divided in to 4 groups as follows: group 1: general control group, group 2: swimming group A, the animales were decapitated after performing 30-minute acute swimming exercise, group 3: sSwimming group B, the animals were decapitated 24 hours after performing 30-minute acute swimming exercise and group 4: swimming group $\mathrm{C}$, the animals were decapitated 48 hours after performing 30-minute acute swimming exercise. Blood samples were collected from all experimental animals by decapitation method and plasma melatonin levels were determined according to RIA method. Results: The comparison of plasma melatonin levels among groups revealed that group 3 had the highest plasma melatonin levels $(p<0.01)$. The levels in group 1 (control) and group 4 were not different. The lowest plasma melatonin levels were found in group $2(p<0.01)$.

Conclusion: The results of our study demonstrate that plasma melatonin levels that decrease immediately after acute swimming exercise increase significantly after 24 hours and restore to resting levels after 48 hours (Tab. 1, Ref. 15). Full Text in PDF www.elis.sk.

Key words: rat, acute swimming exercise, melatonin.
\end{abstract}

There is increasing evidence showing that melatonin can have acute and long-term effects on physical activity and exercise can have acute and long-term effects on melatonin secretion (1-3). In a study investigating the effect of nocturnal exercise on melatonin in rats, the animals were divided into two groups. Group 1 swam in the dark at 00.30 a.m., whereas group 2 was subjected to light for 15 and 30 minutes at the same hour. The concerned study demonstrated that the melatonin content of the pineal gland rapidly decreased in swimming exercise. However, it was noted that activities of $\mathrm{N}$-acetyltransferase (NAT), an important enzyme in melatonin synthesis, did not change. On the contrary, it was seen that melatonin levels in both the pineal gland and plasma decreased in rats which were subjected to light (4). However, in a study including 7 voluntary male subjects, three separate blood samples collected within the 30 seconds, 15 minutes and 30 minutes following exercise showed that there was no significant change in melatonin synthesis after the exercise (5).

A study was conducted in 74 male children 6-7 years of age, with the aim to evaluate the effect of physical activity on cortisol, melatonin and IL-6 secretion in children. 41 children from a public school and 33 children from a football school were chosen and were asked to perform 3 different physical activities. Sa-

${ }^{1}$ School of Physical Education and Sports, Selçuk University, Konya Turkey, and ${ }^{2}$ Department of Physiology, Selcuklu School of Medicine, Selçuk University, Konya - Turkey

Address for correspondence: Dr. Abdulkerim Kasim Baltaci, Selcuk University, Selcuklu Medical School, Department of Physiology, 42031, Konya, Turkey. liva samples were taken before and after the physical activity to evaluate the performance of the subjects and to determine cortisol, melatonin and IL- 6 concentrations. Children from the sports school performed better than those in the general group, however no difference was found between groups in terms of biochemical parameters before and after the exercise. Cortisol, melatonin and IL-6 levels were found to increase after physical activity in both groups (6).

When the results of the studies referred to above are evaluated together, it can be stated that there is no agreement in the literature about how exercise affects melatonin secretion. The aim of the present study is to determine the changes in plasma melatonin levels in rats submitted to acute swimming exercise immediately after the exercise and after 24 and 48 hours. The results of our study can make a contribution to what is known on this topic.

\section{Methods}

\section{Animal material and groups}

This study was conducted on rats provided by Selcuk University Experimental Medicine Research and Application Center (SUDAM). In the study including 40 adult male rats of Spraque Dawley species, the groups were formed as follows:

Group $1(\mathrm{n}=10)$ General Control Group: The group not subjected to any procedure and on a normal diet.

Group $2(\mathrm{n}=10)$ Swimming Group A: The group on a normal diet and decapitated immediately after performing a 30-minute acute swimming exercise. 
Group $3(\mathrm{n}=10)$ Swimming Group B: The group on a normal diet and decapitated 24 hours after performing a 30-minute acute swimming exercise.

Group $4(\mathrm{n}=10)$ Swimming Group C: The group on a normal diet and decapitated 48 hours after performing a 30 -minute acute swimming exercise.

\section{Swimming exercise}

The exercise was performed in a swimming pool, made of heat-resistant glass, $50 \mathrm{~cm}$ high and with a thermostat that kept the water temperature fixed at $37^{\circ} \mathrm{C}$. The exercise was a one-time (30-minute) swimming exercise. The experimental animals were submitted to exercise in pairs at the end of the study and before decapitation. The rats in Group 1 (normal control group) were not submitted to exercise. Blood samples were collected from all the animals by decapitation immediately following the exercise, and 24 and 48 hours after the exercise.

\section{Determination of plasma melatonin}

Plasma melatonin levels were determined in S.U. Meram Medical School Hospital, Central Biochemistry Laboratory using melatonin kit (Melatonin 1-25 RIA DDV BIOCHEMIE GmbH D 35037 Marburg Schwanelle 44) according to radioimmunoassay (RIA) method as $\mathrm{pg} / \mathrm{ml}$.

\section{Statistical evaluations}

Minitab for Windows Release 13.0 package software was used in the statistical evaluation of findings. Arithmetic means and standard errors of all parameters were calculated. Variance analysis was employed to identify differences between groups. Level of significance was set at $\mathrm{p}<0.01$.

\section{Results}

Plasma melatonin levels in the general control group (Group 1 ), which was not subjected to any procedure, were the same as those in group 4, higher than those in group 2 and lower than those in group $3(\mathrm{p}<0.01)$ (Tab. 1). Group 2 (the group decapitated just after the swimming exercise) had lower plasma melatonin levels than groups 1,3 and $4(\mathrm{p}<0.01)$ (Tab. 1). Group 3 (the group decapitated 24 hours after the swimming exercise) had higher plasma melatonin levels than groups 1,2 and $4(\mathrm{p}<0.01)$ (Tab. 1). Plasma melatonin levels in group 4 (the group decapitated 48 hours after the swimming exercise) were the same as those in group 1, higher than those in group 2 and lower than those in group 3 ( $\mathrm{p}<0.01)$ (Tab. 1).

\section{Discussion}

It was observed in our study that plasma melatonin levels in the blood samples collected from the experimental animals immediately after 30-minute acute swimming exercise were significantly lower when compared to those in the control group. There is an increasing evidence pointing out that exercise can have both acute and long-term effects on melatonin secretion (1). However,
Tab. 1. Plasma Melatonin Levels in the Study Groups.

\begin{tabular}{ll}
\hline Groups (n=10) & Melatonin $(\mathrm{pg} / \mathrm{ml})$ \\
\hline Group 1 (General Control Group) & $16.87 \pm 0.91 \mathrm{~b}$ \\
Group 2 (Swimming Group A) & $11.57 \pm 0.81 \mathrm{c}$ \\
Group 3 (Swimming Group B) & $31.19 \pm 1.19 \mathrm{a}$ \\
Group 4 (Swimming Group C) & $16.60 \pm 0.99 \mathrm{~b}$ \\
\hline
\end{tabular}

*Mean values with different superscripted letters in the same column are statistically significant $(\mathrm{p}<0.01)$.

results of the studies exploring the relation between melatonin and exercise are inconsistent. It was reported that physical activity did not cause any change in melatonin levels of female athletes. ${ }^{7}$ However, in a study carried out on children, Perez Navero et al (6) showed that physical activity significantly increased melatonin levels. Similarly, Carr et al (8) reported a significant increase in plasma melatonin levels of females after exercise. The results of the mentioned studies are inconsistent with the decreased plasma melatonin levels we observed at the end of acute swimming exercise. In a study including 7 healthy males, nocturnal physical activity was shown to result in a significant reduction in plasma melatonin levels (9). This finding is noteworthy, as melatonin secretion increases at night (10). The fact that despite this increase, nocturnal physical activity significantly inhibited plasma melatonin levels at the time when the levels were the highest (9) is an impressive example of the relation between exercise and melatonin. The finding reported by Monteleone et al (9) to the effect that nocturnal physical exercise led to a significant decrease in melatonin levels is an important one supporting our finding of decreased melatonin levels immediately after exercise. However, the most remarkable finding with which we can directly compare ours was put forth in the study carried out by Yaga et al (4). Yaga et al (4) demonstrated that swimming exercise caused a dramatic decrease in the melatonin content of the pineal gland in Spraque Dawley species rats. The results of this study are consistent with the decreased plasma melatonin levels we found in the experimental animals immediately after acute swimming exercise.

The highest plasma melatonin levels in the present study were obtained 24 hours after the acute swimming exercise. It was reported that exercise could lead to acute changes (within minutes) in melatonin levels and could also cause changes in the rhythmic secretion of melatonin for 12-24 hours after an acute exercise. The acute effects of exercise on melatonin levels depend on the type, intensity and duration of exercise (11). Bullen et al (12) reported that exercise significantly increased plasma melatonin levels in 7 young women attending an 8 -week aerobic course. It was claimed in a study including healthy adult men that melatonin levels that increased just after physical activity were restored to resting levels one hour after the exercise (13). The results of these studies are contradictory with ours. We found in our study that plasma melatonin levels that fell down immediately following the acute swimming exercise significantly increased after 24 hours. As Buxton et al (11) suggest the major factor determining the exercise-dependent changes in melatonin levels is the type, intensity and duration of exercise. The inconsistency between the reports, results of which were quoted above, and our study may have resulted from such 
differences in exercise. Skrinar et al (14) reported that effort exercise could lead to a decrease, not an increase, in melatonin levels. These findings of the said researchers partly support our results, as we also found decreased plasma melatonin levels immediately following the exercise. However, we also found increased plasma melatonin levels 24 hours after the exercise. Monteleone et al (15) noted that plasma melatonin levels could increase for 5 hours after physical activity. This finding of theirs may be considered consistent with the increased plasma melatonin levels we obtained 24 hours after the exercise.

In our study, the plasma melatonin levels we observed 48 hours after acute swimming exercise were not different than those in the control group. This result indicates that changes in melatonin levels after acute swimming exercise are restored to resting values after 48 hours. Several researchers reported that the stress caused by physical activity brought about changes in melatonin secretion (1, $9,11-15)$. Although there is an agreement that exercise results in changes in melatonin levels, there are contradictory results concerning the direction of these changes.

The results of our study demonstrate that plasma melatonin levels that fall down immediately after acute swimming exercise increase significantly after 24 hours and are restored to resting levels after 48 hours. The findings presented in this study can contribute to what is known on this topic. Depending on the findings of our study>

1) Acute swimming exercise leads to an inhibition of plasma melatonin levels in rats.

2) Plasma melatonin levels that decrease immediately after acute swimming exercise significantly increase after 24 hours.

3) Plasma melatonin levels are restored to resting levels 48 hours after acute swimming exercise.

It can be stated in conclusion that exercise leads to significant changes in plasma melatonin levels and that there is a significant relation between pineal gland and exercise.

\section{References}

1. Buxton OM, L'Hermite-Baleriaux M, Hirschfeld U, Cauter E. Acute and delayed effects of exercise on human melatonin secretion. J Biol Rhythms 1997; 12 (6): 568-574.

2. Mazepa RC, Cuevas MJ, Collado PS, Gonzales-Gallego J. Melatonin increases muscle and liver glycogen content in nonexercised and exercised rats. Life Sci 2000; 66 (2): 153-160.
3. Meeking DR, Wallace JD, Cuneo RC, Forsling M, Russel-Jones DL. Exercise-induced GH secretion is enhanced by the oral ingestion of melatonin in healthy adult male subjects. Eur J Endocrinol 1999; 141 (1): 22-26.

4. Yaga K, Tan DX, Reiter RJ, Manchester LC, Hattori A. Unusual reponses of noctural pineal melatonin synthesis and secretion to swimming: attempts to define mechanisms. J Pineal Res 1993; 14 (2): 98-103.

5. Elias AN, Wilson AF, Pandian MR, Rojas EJ, Kayaleh R, Stone SC, James N. Melatonin and gonadotropin secretion after acute exercise in physically active males. Eur J Appl Physiol 1993; 66 (4): 357-361.

6. Perez-Nevero JL, Jaraba-Caballero S, Ibarra de la Rosa I, JarabaCabellero MP, Guilen del Castillo M, Montilla-Lopez P, Tunez-Finana I, Romanos-Lezcano A. Effects of competitive physical exercise on neuroendocrine response and interleukin-6 liberation in children. Ann Esp Pediatr 1999; 51 (3): 267-272

7. Ronkainen H, Vakkuri O, Kauppila A. Effects of physical exercise on the serum concentration of melatonin in female runners. Acta Obstet Gynecol Scand 1986; 65 (8): 827-829.

8. Carr DB, Reppert SM, Bullen B, Skrinar G, Beitins I, Arnold M, Rosenblatt M, Martin JB, McArthur JW. Plasma melatonin increases during exercise in women. J Clin Endocrinol Metab 1981; 53 (1): 224-225.

9. Monteleone P, Maj M, Fusco M, Orazzo C, Kemali D. Physical exercise at nightblunts the nocturnal increase of plazma melatonin levels in healthyhumans. Life Sci 1990; 47 (22): 1989-1995.

10. Reiter R. Pineal melatonin, cell biology of its synthesis and of its physiolgical interactions. Endocr Rev 1991; 12 (2): 151-180.

11. Buxton OM, Frank SA, L'Hermite-Baleriaux M, Leproult R, Turek FW, Van-Cauter E. Roles of intensity and duration of nocturnal exercise in causing phase delays of human circadian rhythms. Am J Physiol 1997; 273 (3): 536-142.

12. Bullen, BA, Skrinar GS, McArthur JW, Carr DB. Exercise effect upon plasma melatonin levels in women: possible physiological significance. Can J Appl Sport Sci 1982; 7 (2): 90-97.

13. Theron JJ, Oosthuizen JM, Rautenbach MM. Effect of physical exercise on plasma melatonin leves in normal volunteers. S Afr Med J 1984; 66 (22): 838-841.

14. Skrinar GS, Bullen BA, Reppert SM, Peachey SE, Turnbull BA, McArthur JW. Melatonin response to exercise training in women. J Pineal Res 1989; 7 (2): 185-194.

15. Monteleone P, Maj M, Franza F, Fusco R, Kemali D. The human pineal gland responds to stress-induced sympathetic activation in the second half of the dark phase: preliminary evidence. J Neural Transm Gen Sect 1993; 92 (1): 25-32. 